Portland State University

PDXScholar

5-8-1979

\title{
A Comparison of Maternal Remarks to Normal and Language Delayed Children
}

Vanessa Jow Bunker

Portland State University

Follow this and additional works at: https://pdxscholar.library.pdx.edu/open_access_etds

Part of the Communication Commons, and the Speech Pathology and Audiology Commons Let us know how access to this document benefits you.

Recommended Citation

Bunker, Vanessa Jow, "A Comparison of Maternal Remarks to Normal and Language Delayed Children" (1979). Dissertations and Theses. Paper 2785.

https://doi.org/10.15760/etd. 2780

This Thesis is brought to you for free and open access. It has been accepted for inclusion in Dissertations and Theses by an authorized administrator of PDXScholar. Please contact us if we can make this document more accessible: pdxscholar@pdx.edu. 
AN ABSTRACT OF THE THESIS OF Vanessa Jow Bunker for the Master of Science in Speech Communication with an emphasis'in Speech Pathology/Audiology presented May 8, 1979.

Title: A Comparison of Maternal Remarks to Normal and Language Delayed Children.

APPROVED BY MEMBERS OF THE THESIS COMMITTEE:

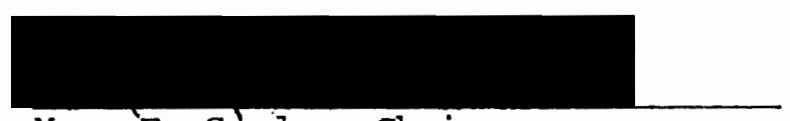

Mary E. Gdrdon, Chairperson

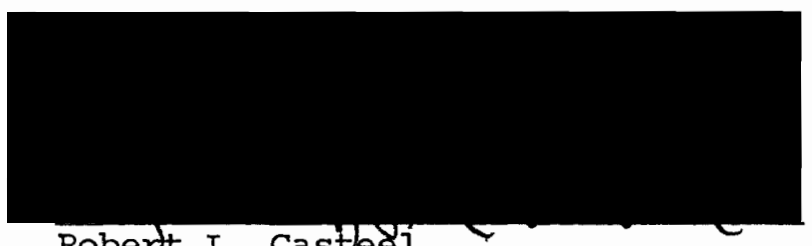

Robert I. Casteel

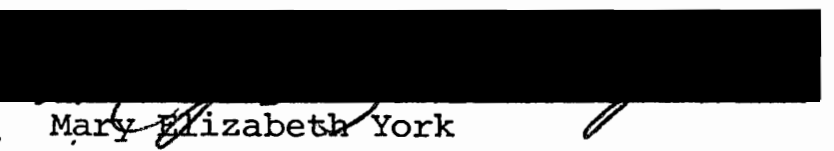

This investigation compared maternal remarks to language delayed offspring and maternal remarks to normal language developing offspring in an attempt to determine if and where differences occurred. The following questions were asked:

1) Do mothers of language delayed children present their children with a significantly different percentage of verbal constraints (commands and questions) than do mothers of normal language developing children in 
a play situation?

2) Do mothers of language delayed children present their children with an equal number of utterances as mothers of normal language developing children in a play situation?

3) Is the maternal mean length of response equal?

4) Do mothers of language delayed children present their children with a significantly different percentage of types of remarks than mothers of normal language developing children?

Mothers of twenty pre-school children were chosen from Washington County Head Start (Oregon) to serve as subjects. The subjects were divided into two groups on the basis of language sikill level of their children. The control group was composed of ten mothers whose offspring demonstrated language skills at age level according to the Utah Test of Language Development (UTLD) (Meacham, Jex and Jones, 1967). The experimental group consisted of ten mothers whose offspring demonstrated a minimum of six months delay in language skills as measured by the UTLD. All children demonstrated language skills between 2 years, 6 months and 3 years, 6 months. The mean chronological age for offspring in the control group was 3 years, 0 months; mean age for offspring in the ex-. perimental group was 4 years, 3 months. All offspring were matched for language age equivalency. All families reported incomes at or below the poverty level most recently established by the federal government.

Maternal usage of verbal constraints (commands and questions), number of utterances, mean length of response, echoics, expansions, labels, parallel talk, self talk, and other remarks were compared, using two-tailed $\underline{t}$-tests for independent means. The results indicate a statistically significant difference exists between the two groups at the 0.05 
level of probability for parallel talk and self talk. Mothers of normal language developing children used a significantly higher percentage of parallel talk and self talk than mothers of language delayed children. No other statistically significant differences were found.

In examining the data from this study, it was concluded:

1) There was no statisticalyy significant difference in percentage of yerbal constraints used by mothers of language delayed and normal language developing children.

2) There was no statistically significant difference in total number of utterances in a ten minute period.

3) There was no statistically significant difference in mean length of response,

4) Mothers of normal language developing children used a significantly higher percentage of parallel talk and self talk than mothers of language delayed children.

Perhaps results of this study indicate that teaching parents parallel talk and self talk may be an effective remediation tool for young language delayed children. 
A COMPARISON OF MATERNAL REMARKS TO NORMAL AND LANGUAGE DELAYED CHILDREN

BY

VANESSA JOW BUNKER

A thesis submitted in partial fulfillment of the requirements for the degree of

MASTER OF SCIENCE IN SPEECH COMMUNICATION:

with an emphasis in

SPEECH PATHOLOGY/AUDIOLOGY

Portland State University

1979 
TO THE OFFICE OF GRADUATE STUDIES AND RESEARCH:

The members of the Committee approved the thesis of Vanessa Jow Bunker presented May 8, 1979.

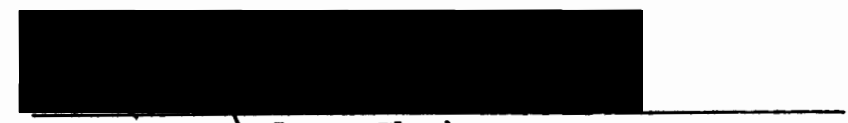

Mary E. Gdrdon, Chairperson
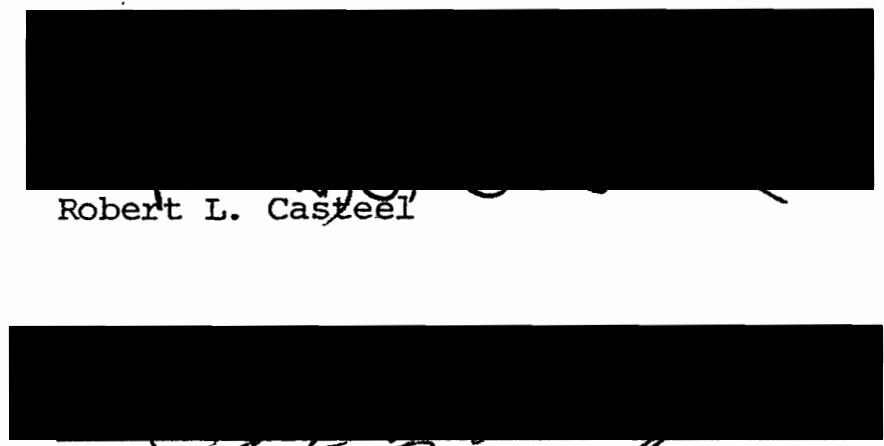
Mary ETfrabeth Yak

APPROVED : Robert w. Vogelsang/ Head, Department of
Speech Commufication

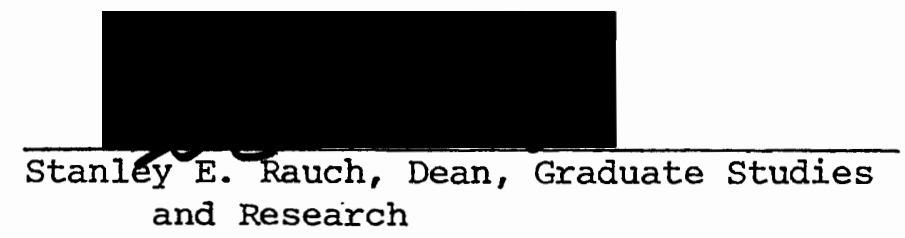




\section{ACKNOWLEDGMENTS}

I wish to thank the members of my thesis committee, Mary E. Gordon and $\mathrm{Dr}$. Robert Casteel, whose guidance enabled me to complete my thesis. I also wish to thank Mary Elizabeth York whose comments were helpful and whose interest in this project was inspiring. Special thanks are extended to Mary E. Gordon, chairperson of my thesis committee, whose guidance, interest, and clear thinking were invaluable in completing this goal.

I also wish to acknowledge the co-operation and interest extended by mothers of children enrolled in Washington County Head Start. Their interest and eagerness to participate in this study was appreciated.

Most of all, I wish to thank my husband, Tom. His infinite patience, love, encouragement, and sacrifices enabled me to undertake this project. Thank you, Honey! 
TABLE OF CONTENTS

PAGE

ACKNOWLEDGEMENTS. $\ldots \ldots \ldots \ldots \ldots \ldots \ldots \ldots \ldots \ldots \ldots \ldots \ldots \ldots \ldots \ldots \ldots$

IIST OF TABLES. $\ldots \ldots \ldots \ldots \ldots \ldots \ldots \ldots \ldots \ldots \ldots \ldots \ldots \ldots \ldots \ldots \ldots \ldots$

CHAPTER

I INTRODUCTION AND STATEMENT OF PURPOSE ............. 1

INTRODUCTION $\ldots \ldots \ldots \ldots \ldots \ldots \ldots \ldots \ldots \ldots \ldots \ldots \ldots \ldots \ldots \ldots$

STATEMENT OF PURPOSE $\ldots \ldots \ldots \ldots \ldots \ldots \ldots \ldots \ldots \ldots \ldots \ldots \ldots$

DEFINITION OF TERMS $\ldots \ldots \ldots \ldots \ldots \ldots \ldots \ldots \ldots \ldots \ldots \ldots$

II REVIEW OF THE LITERATURE ................... 8

ADULT IANGUAGE TO NORMAL CHILDREN ............ 8

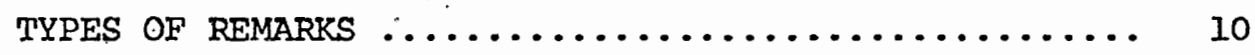

PARENTAL USE OF VERBAI CONSTRAINTS ............ 12

METHODS OF CLINICAL INTERVENTION .............. 14

IMPAIRED FEEDBACK AND USE OF CONSTRAINTS ......... 15

III METHODS AND PROCEDURES $\ldots \ldots \ldots \ldots \ldots \ldots \ldots \ldots \ldots \ldots \ldots \ldots \ldots$

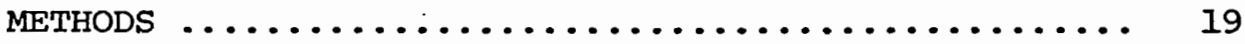

Description of Subjects

Instrumentation

PROCEDURES $\ldots \ldots \ldots \ldots \ldots \ldots \ldots \ldots \ldots \ldots \ldots \ldots \ldots \ldots \ldots \ldots \ldots . \ldots 21$

Experimental Conditions

Scoring and Data Analysis 
IV RESULTS AND DISCUSSION $\ldots \ldots \ldots \ldots \ldots \ldots \ldots \ldots \ldots \ldots$

RESULTS .................................. 24

DISCUSSION OF RESUITS $\ldots \ldots \ldots \ldots \ldots \ldots \ldots \ldots \ldots \ldots \ldots \ldots \ldots$

$\checkmark \quad$ SUMMARY AND IMPLICATIONS $\ldots \ldots \ldots \ldots \ldots \ldots \ldots \ldots \ldots \ldots \ldots \ldots$

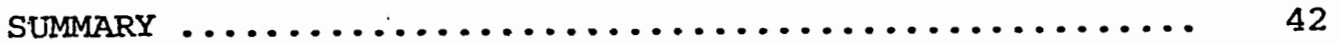

IMPLICATIONS $\ldots \ldots \ldots \ldots \ldots \ldots \ldots \ldots \ldots \ldots \ldots \ldots \ldots \ldots \ldots \ldots$

Clinical

Research

SELECTED BIBLIOGRAPHY $\ldots \ldots \ldots \ldots \ldots \ldots \ldots \ldots \ldots \ldots \ldots \ldots \ldots \ldots \ldots \ldots \ldots \ldots \ldots$

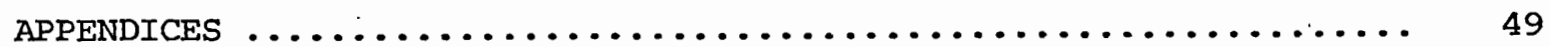

A IAANGUAGE AGE, CHRONOLOGICAI AGE, AND SEX OF MATCHED OFFSPRING ......................... 49

B ADMINISTRATION FOR CHIIDREN, YOUTH AND FAMILY NOTICE FAMIIY INCOME GUIDELINES FOR $1978 \ldots \ldots \ldots \ldots \ldots \ldots \ldots \ldots \ldots$

C MODIFICATION OF PARENT-CHILD INTERACTION SCORESHEET .... 51

D TRANSCRIPT OF INFORMATION GIVEN TO PARENTS ......... 52

E GUIDELINES FOR COUNTING NUMBER OF UTTERANCES . . . . . . . 53

F GUIDELINES FOR COUNTING MEAN LENGTH OF UTTERANCES . . . . 55 
LIST OF TABLES

TABIE

PAGE

I t-VALUES FOR CATEGORIES OF MATERNAL REMARKS

II MEAN, STANDARD DEVIATIONS, AND t-VALUES FOR NUMBER OF UTTERANCES $\ldots \ldots \ldots \ldots \ldots \ldots \ldots \ldots \ldots \ldots \ldots \ldots \ldots \ldots . \ldots \ldots$

III MEAN, STANDARD DEVIATIONS, AND $t$-VALUES FOR

MEAN LENGTH OF UTTERANCE

IV COMPARISON OF MEAN PERCENTAGES AND STANDARD DEVIATIONS FOR CONTROL AND EXPERIMENTAL REMARK CATEGORIES

V A COMPARISON OF EXPERIMENTAL AND CONTROL SUBJECTS' USE OF VERBAI CONSTRAINTS ............... 29

VI A COMPARISON OF MATCHED SUBJECTS' NUMBER OF UTTERANCES AND MEAN IENGTH OF RESPONSE (MIR) $\ldots \ldots \ldots \ldots \ldots .32$

VII RANK ORDER OF FREQUENCY OF REMARKS .............. 35 
CHAPTER I

INTRODUCTION AND STATEMENT OF. PURPOSE

\section{Introduction}

The beginning of language is one of the most remarkable developments of early childhood. The child progresses rapidly from crying and randomly produced sounds to a communicative individual responding with words, phrases and sentences. This phenomenon has given rise to an abundance of research.

Inquiries into this area have included emphasis on studying. verbal input to the child in an attempt to determine the influence of the child's verbal environment on his acquisition of language. In recent years, the nature of adult to child verbal stimulation has been considered. The verbal models children receive from adults, especially parents, influence acquisition of language. Berry and Eisenson (1956) reported the home atmosphere is an important factor in influencing "Ianguage development. Moerk (1972) described the parents" role as teachers of language. Friedlander, Jacobs, Davis and Wetstone (1972) contended the environment must shape the development of a child's language. Moerk (1976) elaborated by stating that mothers use "a variety of specific techniques to instruct and correct their children during the process of first language acquisition".

Research into the environment and parent-to-child language stimulation has been a topic of much discussion in the literature. Variations in the environment and variations in the quantity and quality of 
parent-to-child stimulation is likely to affect the rate, course, and nature of language acquisition.

One such variable in language development is maternal language to young children. The adequacy of a child's communication skills may be a result of language patterns in the environment. A systematic analysis and comparison of maternal language directed at normal language developing children and language delayed children has the potential for providing a basis for remediation.

\section{Statement of Purpose}

The purpose of this study was to analyze and compare the language used by mothers of language delayed children with the language used by mothers of children with normally developing language when talking with their respective offspring. More specifically, maternal remarks were categorized as follows: parallel talk, self-talk, commands, questions, expansions and modifications, repetitions and echoic remarks, and other remarks. The types of remarks were then compared between the two groups.

The following questions were addressed:

I) Do mothers of language delayed children present their children with a significantly different percentage of verbal constraints (commands and questions) than do mothers of normal language developing children in a play situation?

2) Do mothers of language delayed children present their children with an equal number of utterances as mothers of normal language developing children?

3) Is the maternal mean length of response equal? 
4) Do mothers of language delayed children present their children with a significantly different percentage of types of remarks than mothers of normal language developing children?

\section{Definition of Terms}

The following definitions were utilized for the purpose of this study.

1) Cormand: The term command is a statement made as a directive, indicating an expected verbal or other response.

Each such statement was credited as one command. For example, if the parent said: "Put the dog here. Put the dog in the box. Bring it here," three commands were credited. By contrast, "Can you put the dog here? Put it here," was credited with one command.

2) Constraint: The term constraint as defined by Bayles (1974) refers to any event that interrupts the child's ongoing behavior, including physical limitations, commands and questions. For the purpose of this study, a constraint refers to any verbal event that interrupts the child's ongoing behavior and includes questions and commands.

3) Echoic: The term echoic refers to any verbal behavior that is controlled by verbal stimuli; this behavior is a response that generates a sound pattern similar to that of the stimulus (Skinner, 1957).

Marshall, Hegrenes, and Goldstein (1973) followed Skinner's definition. The following is an example of an echoic:

Parent: "Here is youx blue truck."

Child: "Blue truck" (echoic)

For the purpose of this study, each statement was credited one instance of echoic remark. For example the following interaction was 
credited one echoic:

Child: "Poor man fall down."

Parent: "Poor man fall down." (echoic)

4) Expansion: The term expansion refers to use of a technique of building upon, or adding words, to a grammatically incomplete utterance to form a grammatically complete sentence while maintaining original word order (Brown and Bellugi, 1964).

For the purpose of this study, each statement was credited one expansion. For example, the following interaction yielded two counts of expansions:

Child: "Doggie"

Parent: "That's a big dog. A nice, big dog is in the picture."

5) Intraverbal: The term intraverbal refers to any verbal behavior controlled by stimuli that show no point to point correspondence with the verbal behavior (Skinner, 1957).

Marshall, Hegrenes, and Goldstein (1973) followed Skinner's definition but clarified it by defining it as a verbal response controlled by verbal stimuli, but having no point-to-point correspondence with them. The following is an example of an intraverbal:

Parent: "There might be an extra one."

Child: "There aren't any more." (intraverbal)

6) Label: The term label refers to an utterance that names an object or event.

For the purpose of this study each such statement was credited one label. The following discourse yielded two instances of labels:

Parent: "Oh, a car. Can you drive it? That's a Volkswagen car."

7) Language delayed: For the purpose of this study, the term 
language delayed refers to the condition in which a child's language development is a minimum of six months below chronological age as measured by the Utah Test of Language Development (Meoham, Jex and Jones, 1967).

8) Mand: The term mand is a verbal operant in which the response is reinforced by a characteristic consequence and is therefore under the functional control of relevant conditions of deprivation or aversive stimulation. Mands are verbal behavior that specify consequences (Skinner, 1957).

Marshall, Hegrenes and Goldstein (1973) include demands, commands, and rexplests in. theix tefinition.. Fyamples of mands indlute the follow ing :

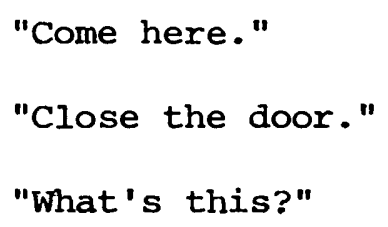

9) Modification: The term modification as defined by Seitz and Stewart (1975) refers to an utterance that amplifies and/or modifies a child's utterance. Modifications occur within three utterances of the child's utterance. They include comments resembling expansions and reductions; they do not qualify as expansions, however, as they are not grammatically complete and/or correct.

The following is an example of a modification:

Child: "My car"

Parent: "Your blue car" (modification)

10) Parallel talk: The term parallel talk refers to a technique of talking out loud about what someone else is doing, seeing, or feeling at the moment (Van Riper, 1972). 
Each statement was credited one instance of parallel talk. For example, the following interaction was credited three instances of paralIel talk:

Parent: "Oh-oh, the frog is stuck. Poor frog can't get out. Owie, his leg is hurt."

11) Question: The term question refers to any request or statement made with an upward questioning inflection at the end.

12) Reduction: The term reduction refers to an utterance which can be considered reduced imitations of utterances. Word order is generally maintained, with some words omitted (Brown and Bellugi, 1964).

13) Repetition: The term repetition refers to the instance where an individual echoes, or repeats exactly; what was said just prior (Seitz and Stewart, 1975).

14) Self talk: The term self talk refers to a technique of talking out loud about what one is doing, seeing, or feeling at the moment (Van Riper, 1972) .

For the purpose of this study, each statement was credited one instance of self talk. For example, the following discourse yielded four instances of self talk:

Parent: "I'm going to the store now. Bye-bye kids. I'm getting out of the car because it's so hot. Going to the store to buy me a new dress."

15) Tact: The term tact refers to a verbal operant in which a response of given form is evoked or strengthened by a particular object or event or property of an object or event (Skinner, 1957).

Marshall, Hegrenes and Goldstein (1973) included names, labels, or utterances that describe, as verbal responses to stimulus in this defini- 
tion. Examples of tacts include the following:

Child: "A cup. That man. Big doggie." 
CHAPTER II

REVIEW OF THE IITERATURE'

How children acquire language has been an issue for debate for many years, with many professions offering their viewpoint. Recent interest has dealt with studying. verbal input to children to determine environmental influences on language acquisition.

\section{Adult Language to Normal Children}

Various aspects of adult-to-child language have been researched. Brown and Bellugi (1964) studied mother-to-child verbal interaction. They found mothers' speech used with children differed from speech used with adults; in comparison, speech to children was simple, short, grammatically correct, imitative, and utilized expansion. Snow (1972) found similar results in a study with adult language to two year old and ten year old children. She noted that mothers' speech to younger children was simpler and more redundant, with modifications in speech styles dependent to some degree upon the reaction of the child.

Broen (1972) investigated the verbal environment of the languagelearning child, and found that mothers' speech used with eighteen to twenty-six month old children was slow, with well marked pauses at sentence boundaries. With this group of children, mothers tended to use a smaller vocabulary range than with children over forty-five months of age, and offered much repetition with no variations. Sentences generated by mothers were classified into two major categories: expansion of im- 
perative sentences and variations of "be" sentences, with "this, that, it, there, or here".

Philips (1971) compared adult-to-adult speech and adult-to-child speech with children ranging in age from eight to twenty-eight months. Adult-to-adult speech was characterized by longer utterances, more verbs per utterance; more modifiers per utterance, a larger proportion of function words, more verb forms, and a smaller proportion of content words. Additionally, differences in syntax, vocabulary and intonation between language addressed to adults and childreh were noted. These differences changed with the age of the person addressed.

Ling and Ling (1974) investigated the extent to which different modes of communication were used during the first three years of life. In contrast to the previous authors, ling and ling reported that neither quantity or type of maternal verbalization varied significantly with the age of the child. Complex sentence forms were used by mothers with almost equal frequency, regardless of the age of the child. When addressing fourteen to twenty-four month old-children, mothers used -simple sentences most frequently, followed by questions, single words, complex sentences, and phrases. With three year old children, 80 percent of maternal utterances included comments or questions about objects or events in the immediate environment. Parental expansions were rare; only 10 in 413 utterances were noted in maternal interactions with fourteen month old to three year old children.

Most research describes mother-child interactions. Giattino and Hogan (1975), however, analyzed the speech of one middle class father with his language learning child. Similarities were noted between the types of sentences generated by the adult male and female adults. Declar- 
ative sentences were most common, followed by questions; repetitions, exclamatory sentences, commands, grammatically incomplete sentences, and completion sentences. Imitations and expansions were rarely noted, a feature that contrasts with some reports of maternal utterances to young children.

In spite of differences, however, the literature indicates that adults do seem to adopt a characteristic sentence pattern and a style of speech as they talk to language learning children. Language used with children during the period in which they develop basic language skills is specialized and not representative of the language adults generally use among themselves.

\section{Types of Remarks}

Various authors have described the types of utterances adults make to children learning language. Brown and Bellugi (1964) recorded data on a mother and her normally developing eighteen month old daughter and on a mother and her normally developing thirty-six month old son over a one year period of time. They described parent-child verbal interaction as a cycle of reductions and expansions for both parent-child combinations. Maternal utterances were characterized as expansions of children's utterances. They reported expansions accounted for 30 percent of maternal utterances. Word order was maintained; but incomplete utterances were expanded to include omitted words, usually functors, to make grammaticalIy complete sentences appropriate to the circumstance. Children's utterances paralleled maternal models, with some words omitted. Words retained generally were limited to nouns, verbs and adjectives.

Seitz and Stewart (1975) investigated nother-child verbal inter- 
actions using two groups, with mean children's ages of 22.7 months and 55.6 months. Except for modifications, no significant differences in frequency of types of utterances were noted between the groups. Fiftythree percent of utterances used by mothers were statements; questions comprised 33 percent; and 8 percent were affirmatives or negatives. The mean percentage for modifications used by mothers of two year old children was 5.3 , as compared to 1.8 percent for mothers of the older group. Mothers' of two year olds used exact repetitions in 3.6 percent of the utterances in contrast to mothers of older siblings whose repetitions comprised 1.1 percent.

Reichle, Ionghurst and Stepanich (1976) described some interactions used in mother-child verbal communication for mothers of two year olds and mothers of three year olds. They found no significant difference between the mean number of utterances for the two groups. No difference between the groups was noted for percentage of expansions, simple modeling, and direct imitation. Mothers of three year olds used a higher percentage of modeled questions.

Malouf and Dodd.(1972) studied the importance of exposure, imitation and expansion on the acquisition of a grammatical rule. They demonstrated one of three learning conditions to eighty-four first grade children. These conditions included: 1) exposure, in which the subject was exposed to figures and recorded sentences, but made no overt responses to training trials, 2) imitation, in which the subject was exposed to a figure and recorded sentences and asked to describe the figure orally, and 3) expansion, in which the subject was shown the figure and asked to describe it, followed by a presentation of the recorded sentences. Results showed imitation and expansion were more effective in teaching new 
grammatical constructs than exposure. Additionally, they found no significant differences in the effectiveness of either the imitation or expansion method.

Cazden (1969) experimented with three conditions in treating language delayed children. The first group received intensive, deliberate expansions of utterances: The second group received models of an equal number of utterances, designed deliberately to be stimuli other than expansions. The third group acted as a control group, and received no stimulation. Results indicated that modeling was a more effective tool than expanding: ' Cazden explains why this may be so:

The surprising finding that expansions did not help as much as modeling suggests that richness of verbal stimulation may be a more critical feature of the child's language environment than is the direct contingence of the adult's response. Expansions are by definition contingent on the child's speech in context, as well as timing. To the extent they are pure expansions, just filling in the child's utterance to make the nearest complete sentence, they have less variety of vocabulary and grammatical patterns than the adult non-expanded speech. The suggestion that the richness-impoverishment dimension is critical thus gains support.

\section{Parental Use of Verbal Constraints}

Results of some studies of parent-child interaction have focused on parental usage of verbal constraints with offspring, notably use of commands and questions. In a comparison of mother-child interactions between normal and developmentally delayed groups, Terdal, Jackson and Garner (1976) found significant differences in reference to response patterns of children to parental initiations. Measurements were taken in both free play and structured task situations. Delayed subjects were divided into low mental age, mid-mental age and high mental age groups. Divisions by chronological age were made for normally developing groups. 
In free play situations, the low mental age group responded to maternal interaction 49 percent of the time. Little difference was found between the mid-mental age ( 81 percent) and the high mental age ( 80 percent) groups. This contrasts to consistently high levels of mother-child interactions of 86 percent to 90 percent among the groups of normal children. In the task situation, parents were asked to have the child complete a series of specified tasks. For the low mental age group, nearly 70 percent of all behaviors emitted by mothers were commands. The percentages were 30 percent and 35 percent for the mid-mental age and high mental age groups. This contrasts with 37 percent for the two to four year old group, 26 percent for the four to seven year old group, and 31 percent for the six to eight year old group. Marshall, Hegrenes, and Goldstein (1973) found similar results and differences between maternal-child verbal interactions of twenty mothers with retarded offspring and twenty mothers with normal offspring. Data were collected on frequency of four verbal operants: mands, tacts, intraverbals, and echoic responses. Non-retarded children used tacts, mands, and intraverbals with greater frequency than retarded children. Retarded children echoed more frequently. Maternal usage of tacts, intraverbals and echoics were similar; however, mothers of retarded children used a greater frequency of mands.

Wulbert, Inglis, Kriegsmann, and Mills (1975) researched home environments and mother-child interactions. of twenty language delayed pre-schoolers and a matched control group of normal pre-school children, using the Caldwell Inventory of Home stimulation. Twenty pre-school children with Down's Syndrome were included as a second control group to isolate the effects of maternal reactions to handicapped children. 
Children were distributed across all socio-economic strata. Results indicated the language delayed group had significantly lower scores in five of six categories measured by the Caldwell. Greatest differences were found in the emotional and verbal responsiveness of the mother, followed by avoidance of restriction and punishment. The authors report that although children from both groups were observed to behave in ways that displeased their mothers, mothers of normal children generally tried to reason with the child. In contrast, mothers of language delayed children tended to shout, threaten, and spank the child. There also was significant difference in maternal involvement with the child. There was little difference between Caldwell scores of parents of normal children and parents of children with Down's Syndrome, suggesting that mothers may not necessarily behave differently towards developmentally different children, but that maternal interaction may affect both the child's cognitive development and how he uses language.

\section{Methods of Clinical Intervention}

Seitz and Hoekenga (1974) entertained the hypothesis that the use of modeling procedures would change parent-child interaction patterns, resulting in increased verbal interactions. They experimented with four mentally retarded subjects in a clinical training program in which parents observed and described clinician-child interactions before replacing the clinician. All four children increased their mean length of response. Three children increased the number of utterances. The authors concluded that parents' verbal behavior changed in different ways, accommodating to individual children, but increasing overall interaction; these changes were learned through observing the clinician-child inter- 
action. Changes were characterized by an increase in positive parental responsiveness and a decrease in parental directiveness.

sietz and Riedell (1974) targeted an increase in parent-child interactions as a language treatment goal in treating a severely retarded four year old female. Parents observed and described interactions between clinicians and the child for approximately six sessions before they practiced the behaviors modeled. Results recorded immediately after treatment demonstrated changes in the desired direction, i.e., increased parent-child interactions. Moreover, parental responses appeared to be more positive, with increases in praise and use of commands to instruct in how to complete an activity, rather than switching activities.

Seitz's premise in both these studies was the notion that constraints, in the form of a high rate of parental commands, do not result in a high rate of compliance. Accordingly, parents were trained by observing various clinician-child interactions designed to facilitate communication by allowing the child to direct activities, commenting on the child's activities, while avoiding questions and commands. These observations were discussed. The parent was never directed on what to do, but chose behaviors she observed. General findings indicate that mothers tended to decrease frequency of questions and commands, or modified them to follow the lead of their child's play, while increasing frequency of comments. The majority of children demonstrated increases in number of utterances and mean length of response.

\section{Impaired Feedback and Use of Constraints}

Several authors have entertained the hypothesis that the language 
delayed child's feedback to parents influences use of parental constraints. As parent-child verbal communication may be viewed as a dyadic process, data must be reviewed with this consideration.

Terdal, Jackson and Garner (1976) interpreted the incidence of increased commanding by parents of developmentally delayed children as an occurrence of parental response to inadequate responses from their children by increasing structure. They hypothesized that because developmentally delayed children give parents fewer cues as to how to adapt language, parents respond by increasing structure.

Marshall, Hegrenes and Goldstein (1973) accounted for a high frequency of manding by parents of retarded children by suggesting retarded children may require more external control by the parent, exercised in the form of manding. They theorized that eventually, as this becomes a habitual response generalizing to play situations, other forms of verbal interactions (tacts, intraverbals, and echoic responses) are extinguished by the child's verbal deficits, leaving the parent with manding as a habitual response. In addition, the child may respond to maternal mands motorically, reinforcing parental manding.

Seitz and stewart (1975) agree that certain aspects of the child's language may influence maternal sentence length by eliciting certain types of utterances. Maternal mean length of utterance correlated with frequency of younger children's elicited utterances, indicating that mothers may be gauging the young child's understanding of language by his responsiveness to their questions. They explained that the pattern of results suggests that as children become more proficient at speaking for themselves, mothers expand proportionately fewer utterances. Cunningham and Reuler (unpublished, 1977) coded and analyzed 
verbal interactions of twenty normal and twenty mild to moderately retarded children and their mothers. The Developmental sentence Scoring procedure yielded a description of linguistic and grammatical characteristics of interactive speech. Mothers of the retarded group spoke at a significantly higher language: level than mothers of normal children. This was associated with less frequent compliance to maternal directives, fewer appropriate responses to interactions and questions, and higher levels of independent play in the retarded group. The authors suggested results indicate retarded children provide insufficient behavioral and verbal feedback for the appropriate adjustment of maternal language complexity.

Seitz and Marcus (1976) reported that normally developing children develop skills at a predictable rate and provide parents with consistent cues as to their level of comprehension. Seitz and Marcus elaborate:

When children do not develop normally, they may present confusing cues and reduced responsiveness to their parents. Impaired and confusing feedback from retarded children has been shown to produce parental uncertainty which is expressed by a high rate of inefficient commanding and intrusiveness.

The directionality of this feedback has not been firmly established in reports reviewed. It was not determined whether findings indicated a situation where lowered responsiveness to commands results in a higher frequency of constraints, or whether a high frequency of verbal constraints results in reduced compliance. By describing the types of language mothers present to their language delayed children, and comparing findings to types of language mothers present to normally developing children, a basis for intervention strategy and further research regarding optimum language stimulation for the young language delayed 
child can be established. 
CHAPTER III

METHODS AND PROCEDURES

\section{Subjects}

The subjects utilized in this study consisted of twenty mothers and their natural offspring. The experimental group consisted of ten mothers and their language delayed children; children were considered language delayed if at least six months delayed, with a language age of between 30 and 42 months. Chronological age for children in the experimental group ranged from 3 years, 4 months to 4 years, 11 months, with a mean age of 4 years, 3 months. The experimental group included 6 males and 4 females. (Appendix A) These children were selected from the Washington County Head start population in Oregon.

The control group consisted of ten mothers and their normal language developing children; these children had a language age of between 30 months and 42 months. Chronological age for children ranged from 2 years, 7 months to 3 years, 7 months, with a mean age of 3 years, 0 months. These children were siblings of children enrolled in washington County Head start. The control group included 6 males and 4 females (Appendix A). All families reported gross annual incomes reflecting placement at or below the poverty line most recently established by the federal government (Appendix B).

Children in the control group were matched with children in the experimental group for language age to withị \pm 2 months. Ali children were monolingual. Each mother was judged to be proficient in the use of 
American English; each mother's hearing was also judged to be adequate for conversation. These judgements were made by this investigator during a brief conversational interaction before each mother's participation. Children with physical and/or previously identified mental handicaps were excluded. All children demonstrated hearing wịthin normal limits at the time the parent-child interaction was conducted, as measured by standard audiometric screening procedures at 20 dB from 500 $\mathrm{Hz}$ through $6000 \mathrm{~Hz}$ bilaterally.

\section{Instrumentation}

The Utah Test of Language Development (Mecham, Jex and Jones, 1967), a receptive and expressive language instrument, was used to evaluate the language age of each child. This instrument provides an overall indication of language skills by assigning a language age equivalency to the total score. Ianguage age equivalents are provided for children ranging in age from 0 years, 9 months to 16 years, 0 months. All children scored a language age between 30 and 42 months.

The Parent-Child Interaction Scoresheet, developed at the Portland Center for Hearing and Speech, is an enumerative device for measurement of parental interactive remarks to offspring. A modification of this scoresheet was used to code and analyze maternal remarks into the following categories: parallel talk, self talk, commands, questions, labels, expansions, echoics, and other remarks (Appendix C).

All interactions were recorded by a portable Bell and Howell cassette tape recorder, Model 2081 B, equipped with a condensor microphone.

A portable Beltone audiometer, model 10D, was used to screen 
children's hearing.

\section{Procedures for Describing Remarks}

After completion of each day's sessions, transcripts of maternal remarks from 15 minute recoraings were prepared by the investigator. Only the last 10 minutes were transcribed to allow the subjects a warmup period. All remarks of the child and unintelligible remarks by the mother were excluded from all tallies.

\section{Procedures}

Each mother spent 15 minutes with her child. This interaction period was recorded on cassette tape. The last 10 minutes of this interaction was transcribed by the investigator. Each mother was instructed to play with and talk with her child just as she would at home. Each mother was informed that the purpose of the study was to observe and record speech and language of various aged. children and their mothers. Additionally, each was told her remarks would be compared with remarks of other mothers with children of different ages, and that these remarks would be analyzed. A verbatim transcript of information and instruction given to each parent is contained in Appendix D:

The sessions were conducted in a carpeted room, with only the child and parent present in the room. A Bell and Howell recorder model 2081 D was placed in the room out of the child's vision to record the sessions. To aid the mother-child interaction, a set of toys was provided for subjects to use at their discretion. Six different toys were provided. 
Scoring and Data Analysis

Maternal remarks were transcribed and categorized for both the experimental and control groups. The following procedures were used in describing maternal remarks.

1) Percentage of verbal constraints was calculated by dividing all maternal commands and questions by the total number of remarks made by the mother.

2) Number of utterances was calculated by summation of all remarks made to child. Protocol for counting utterances was adapted from Lee's (1974) method for sentence analysis (Appendix E).

3) Mean length of response was calculated by determining the mean number of words per utterance; total number of words was divided by total number of utterances. Protocol for counting words followed Johnson, Darley, and Spriesterbach's (1963) method for computing Mean Length of Response (Appendix F).

4) Percentage of remarks per category was calculated by dividing remarks in each category by total number of remarks.

The mean and standard deviation of the percentage of verbal constraints was calculated for both groups to compare maternal remarks. The two-tailed $t$-test for independent means was used to determine the degree of difference in remarks between the two groups. Ail.t-values were compared with the 0.05 level of probability. The same test and data analysis were performed for the following comparisons:

1) A comparison of number of utterances

2) A comparison of mean length of response

3) A comparison of percentage of echoics 
4) A comparison of percentage of expansions

5) A comparison of percentage of parallel talk remarks

6) A comparison of percentage of self talk remarks

7) A comparison of percentage of labels, and

8) A comparison of percentage of other remarks. 
CHAPTER IV

\section{RESULTS AND DISCUSSION}

\section{RESUITS}

This study was conducted to determine if mothers of language delayed childxen speak differently to their offspring than mothers of children with normally developing language skills. Parental remarks to offspring :were compared for two groups of mothers: a control group whose offspring demonstrated language skills at age level and an experimental group whose offspring demonstrated a minimum of six months delay behind their chronological age. Offspring of the experimental group were matched to offspring of the control group for language age equivalency.

The first question asked was: Do mothers of language delayed children present their children with a significantly different percentage of verbal constraints than do mothers of normal language developing children in a play situation? The percentage of maternal remarks categorized as commands and questions were compared for the two groups re-": sulting in a t-value of $1.99($ d.f.=19). Although the experimental group presented their offspring with a greater percentage of verbal constraints when compared to the control group, a statistically significant difference was not shown at the 0.05 level of probability (Table I). The two categories of questions and commands were independently analyzed. In comparing the use of questions between the two groups, a t-value of $0.64(\mathrm{~d} . \mathrm{f} .=19)$ was obtained, indicating no statistically significant difference. For commands, a $t$-value of 2.07 (d.f.=19) was 
TABIE I

t-VALUES FOR CATEGORIES OF MATERNAI REMARKS

Remark Category

$\underline{t}$

d.f.

$\mathrm{p}$

Verbal Constraints

1.99

19

$>.05$

Questions

0.64

19

$>.05$

Commands

2.07

19

$p .05$

Echoics

$-1.55$

19

$>.05$

Expansions

0.88

19

$>.05$

Labels

0.44

19

$p .05$

Other

0.71

19

$p .05$

Paxallel Talk

$-2.34$

19

$\triangleleft .05 *$

Self Talk

2.44

19

$<.05 *$

* significant at .05 level

obtained; this value trends toward significance although it is not significant at the 0.05 level of probability. Mothers of normal language developing children commanded less than mothers of language delayed children.

The second question asked was: Do mothers of language delayed children present their children with an equal number of utterances as mothers of normal language developing children in a play situation? Mothers comprising the control group made more remarks to their offspring than mothers comprising the experimental group (Table II). The t-value of -0.69 demonstrated this difference is not significant at the 0.05 level of probability. 
The third question asked.was: Is the maternal mean length of utterance equal? A comparison between the experimental and control mean

TABIE II

MEAN; STANDARD DEVIATIONS, AND $t$ VAIUES FOR NUMBER OF UTTERANCES

$\begin{array}{lccc}\text { Group } & \text { Mean } & \text { S.D. } & \text { t-Value } \\ \text { Control }(\mathrm{N}=10) & 114.30 & 51.68 & \ddots .69 \\ \text { Experimental }(\mathrm{N}=10) & 98.00 & 53.31 & \end{array}$

* NS

length of utterance revealed no statistical difference (Table III). The t-value of $-0.54(d . f .=19)$ was considerably above the 0.05 level of significance.

TABIE III

MEAN, STANDARD DEVIATIONS, AND t-VALUES

MEAN LENGTH OF UTTERANCE

Group

Mean

S.D.

$\underline{t-V a l u e}$

Control $(\mathrm{N}=10)$

Experimental $(\hat{N}=10)$
3.72

3.52
.66

.91

* NS

The fourth question asked was: Do mothers of language delayed children present their children with a significantly different percentage of types of remarks than mothers of normal language developing children? When all categories were analyzed, t-tests revealed significance beyond 
the 0.05 level of confidence in two of the eight categories (Table I). A t-value of:-2.34. $(a . f .=19)$ was found for the percentage of parallel talk used. Control group mothers used parallel talk significantly more often than mothers of language delayed children (Table IV). Significance was shown in the category of self talk (t-value=2.44; d.f.=19). The mean scores shown in Table IV demonstrate the control group mothers used more self talk than mothers of language delayed children.

TABLE IV

COMPARISON OF MEAN PERCENTAGES AND STANDARD DEVIATIONS FOR CONTROI AND EXPERIMENTAI REMARK CATEGORIES

\begin{tabular}{lcccc} 
Remark Category & \multicolumn{2}{c}{ Experimental } & \multicolumn{2}{c}{ Control } \\
& mean & S.D. & mean & S.D. \\
Verbal Constraints & $54.70 \%$ & 15.21 & $42.50 \%$ & 11.92 \\
Questions & $38.80 \%$ & 14.87 & $34.60 \%$ & 14.33 \\
Commands & $15.90 \%$ & 11.08 & $7.80 \%$ & 5.43 \\
Echoics & $2.70 \%$ & 2.98 & $5.10 \%$ & 3.87 \\
Expansions & $1.70 \%$ & 1.76 & $2.70 \%$ & 3.09 \\
Labels & $6.00 \%$ & 7.18 & $4.90 \%$ & 3.21 \\
Other & $23.00 \%$ & 8.98 & $20.40 \%$ & 7.12 \\
Parallel Talk & $10.20 \%$ & 8.21 & $20.40 \%$ & 11.00 \\
Self Talk & $1.60 \%$ & 1.71 & $4.00 \%$ & 2.58
\end{tabular}

These results indicate no statistically significant differences exists between remarks made by mothers of language delayed children and mothers of normal language developing children in any of the following areas: percentage of verbal constraints, number of utterances, mean 
length of response, or usage of expansions, echoics, or labels. Results do indicate, however, the existance of a statistically significant difference between the two groups in maternal usage of parallel talk and self talk. Mothers of normal language developing offspring used a greater amount of parallel talk and self talk.

\section{DISCUSSION}

This investigation sought to answer four questions relative to differences in maternal remarks made to language delayed offspring and normal language developing offspring. The first concern of this study was with the usage of verbal constraints by mothers of language delayed children compared with mothers of normal language developing children. Although the difference in mean percentage of questions posed was not significant, six of the ten mothers in the experimental group used more questions than their matched control (Table V). It is the subjective impression of this investigator that questions (defined for the purpose of this study as any statement or request made with an upward inflection at the end of the utterance) do not always serve as verbal constraints. In many instances, questions were used as a means for the child to demonstrate knowledge, as a mild form of teasing, or as truly requesting permission.

To this investigator, there appeared to be a qualitative difference in the manner in which questions were posed. For example, asking the child, "What is this?" five times consecutively, each time with increasing pitch and volume seemed to be constraining; questions as "Is it a baby?", "Can I guess?", "Where is it?", "Is he happy?", and "What made that funny noise?" did not appear to be constraining. Regardless of vocal 
characteristics, such as volume, pitch and speed (which may act as constraints, or remove constraining qualities), both passages were scored as five questions.

TABLE V

A COMPARISON OF EXPERIMENTAL AND CONTROL 'MOTHERS' USE OF VERBAI CONSTRAINTS

$\begin{array}{cccc}\text { Subjects } & \text { Percentage of } & \text { Percentage of } & \text { Percentage of } \\ \text { Verbal Constraints } & \text { Questions } & \text { Commands }\end{array}$

Experimental 1

Control 1

Experimental 2

Control 2

Experimental 3

Control 3

Experimental 4

control 4

Experimental 5

Control 5

Experimental 6

Control 6

Experimental 7

Control 7

Experimental 8

Control: 8

Experimental 9

Control 9

Experimental 10

Control 10
75

33

53

33

40

27

59

31

71

57

46

60

43

52

60

37

71

52

29

43
57

21

37

26

20

17

56

25

47

53

41

49

29

49

20

30

40

56

52

15

0

25

24
11

14

3

7

19

12

15

7

20

10

3

5

24

4

5

1

.

This investigator believes that, although the data on questions do not reflect differences between the control and experimental groups, 
some differences do exist. Inspection of the transcripts of the verbal interactions indicates that although not every parent in the experimental group used questions in a verbally constraining manner, no mother in the control group used questions in this manner.

In the area of commands, seven of ten mothers in the experimental group used a greater percentage of commands than their matched control (Table V). A comparison of the mean percentage of commands used reveals a difference of 8.10 percent (Table IV). Although not statistically significant, this difference approaches significance and tends to support Marshall, Hegrenes and Goldstein (1973) and Terdal, Jackson and Garner (1976) who found mothers of language delayed children present significantly more commands than mothers of normal children. Marshall, Hegrenes and Goldstein reported mothers of retarded children use mands more frequently than mothers of normal children. One factor which may explain why these authors found significance when this investigator did not may be that different populations were compared. Marshäll, Hegrenes and Goldstein compared normal and retarded children; offspring in this investigation were not considered mentally retarded.

When considering reports from Terdall, Jackson and Garner (1976) that mothers of low developmentally delayed children manded (commanded and questioned) 70 percent of the time; mothers of language delayed children in this study presented fewer commands and questions (54.7 percent). Conversely, mothers of normal children in this investigation presented more commands and questions (42.5 percent) than did the sample in the Terdal, Jackson and Garner study, who reported a command rate of 37 percent for mothers of normal offspring. The differences in percentages reported may be explained by the fact that Terdal, Jackson and 
Garner's data was taken in a structured task situation in which mothers and children completed specified tasks; this investigation was conducted in a free play situation. 'Terdal, Jackson and Garner also included a wider age range in their investigation, which may have accounted for greater or lesser language comprehension skills.

The second area investigated compared the number of utterances spoken in the ten minute sample by mothers of language delayed children and normal language developing children. A comparison of the difference between the mean number of utterances for the two groups reveals the control group used an average of 16.30 more utterances than the experimental group in this ten minute sample. Intragroup examination revealed no pattern of differences as a result of differences in language or chronological age (Table VI). Although results of this question are not statistically significant, this limited observation tends to support Lịng and Iing (1974) and Reichle, Ionghurst and Stepanich (1976). Ising and Ling reported that quantity of maternal verbalizations does not vary significantly, with the age of the child. Reichle, Longhurst and Stepanich found no significant difference between the maternal mean number of utterances to children of different ages.

This question was posed to further examine some authors' beliefs that parents of delayed children experience greater frustration when communicating with their children than parents of normal children (Seitz and Marcus, 1976). The underlying premise of these authors is that if parents of delayed children use more utterances, it may be manifested in more commands or directives, a notion suggested by Texdal, Jackson and Garner (1976) and Marshall, Hegrenes and Goldstein (1973). If on the other hand, they use significantly fewer utterances, the frustration may 
be manifested in a lack of verbal communication.

Although neither of these hypotheses were supported by the results

\section{TABIE VI}

A COMPARISON OF MATCHED SUBJECTS' NUMBER OF UTTERANCES AND MEAN LENGTH OF RESPONSE (MLR)

Experimental 5

Experimental 6

Experimental 8

Control 8

Experimental 9

of this study, it is interesting to note that two parents in the experimental group used a considerably smaller number of utterances to their 
children than other parents in either group; one was credited with a total of five utterances in the ten minute sample and another was credited with forty in comparison to the group mean of 98.00 (Table VI). These two parents had little to say to their offspring; what was said appeared to offer little language stimulation. The mother who made 40 utterances to her child did not make significantly fewer utterances than some of the other mothers.. What was different was the nature of her remarks. Most remarks were classified in the "other" category, and were composed of the following: "Oh my goodness," "Oh my;": "Goodness gracious me", "Oh my yes", "Oh.me, oh my", and other remarks which provide little language information. Remarks of these two mothers may be interpreted as a lack of knowledge regarding language needs of children and/or frustration resulting in little verbạl communication.

The third concern compared the mean length of response between mothers of language delayed children and mothers of normal language developing children. Although no significant difference was found between the groups for mean length of response, a comparison reveals the control group used 0.20 more words per response than the experimental group. This result does not support findings by Philips (1971) who reports length of response increases with the age of the person addressed. Most authors addressing mean length of response compared differences between MIR spoken to adults and MLR spoken to children, rather than MLR spoken to children at various ages (Brown and Bellugi, 1964; Snow, 1972). In other words, rather than comparing adult mean length of response to children of various ages, as this study did, other authors have compared mean length of response to adults with mean. length of response spoken to children. This study neither supports or offers contrary 
evidence to these investigations.

The fourth concern investigated compared different types of remarks made by mothers of normal language developing and language delayed children. The first type of remark analyzed was maternal usage of questions. Mothers in the experimental group used 38.80 percent of their remarks as questions; control group mothers used 34.60 percent. Although the difference is not statistically significant, it does somewhat parallel data reported by Seitz and stewart (1975) who report questions comprised 33 percent of maternal utterances to children 22.7 months and 55.6 months old. This figure is slightly lower than data reported in this study. Ling and Ling (1974) and Giattino and Hogan (1975), however, reported questions occurred second most frequently after other types of remarks in parental verbalizations to normal children. In this investigation, questions occurred most frequently for both groups (Table VII). This difference may be explained partially by the fact that the authors of each investigation counted and analyzed different types of remarks. As no percentages were provided by Ling and Ling or Giattino and Hogan, no further comparison can be made.

The second area analyzed was maternal usage of commands. Mothers in the experimental group used 15.90 percent of utterances as commands, ranking it as the third most frequent type of remark used; control group mothers used 7.80 percent of remarks as commands, ranking it as the fourth most frequently used. This observation approaches significance and tends to support Marshall, Hegrenes and Goldstein's (1973) general finding that mothers of retarded children manded more frequently than mothers of normal children. This finding must be interpreted with caution however, as data varies considerably between the two studies. Marshall, 
TABLE VII

RANK ORDER OF FREQUENCY OF REMARKS

\begin{tabular}{|c|c|c|c|c|c|c|}
\hline Rank & & $\begin{array}{l}\text { Experimental Group } \\
\text { Type of Remark }\end{array}$ & Percent & Rank & $\begin{array}{l}\text { Control Group } \\
\text { Type of Remark }\end{array}$ & Percent \\
\hline 1 & . & Questions & 38.80 & 1 & Questions & 34.60 \\
\hline 2 & . & Other & 23.00 & 2 & Parallel Talk & 20.40 \\
\hline 3 & . & Commands $:$ & 15.90 & 3 & Other & 20.40 \\
\hline 4 & & Parallel Talk & 10.20 & 4 & Commands & 7.80 \\
\hline 5 & $\because$ & Labels & 6.00 & 5 & Echoics & 5.10 \\
\hline 6 & & Echoics & 2.70 & 6 & Labels & 4.90 \\
\hline 7 & : & Expansions & 1.70 & 7 & Self Talk & 4.00 \\
\hline 8 & & Self Talk & 1.60 & 8 & Expansions & 2.70 \\
\hline
\end{tabular}

Hegrenes and Goldstein found that mothers of nonretarded children used 50 percent of utterances as mands (defined as commands and questions by the authors) and mothers of retarded children used 61 percent of utterances as mands. These figures are greater than figures reported in this study; in contrast, this investigation reports 42.50 percent of utterances were categorized as commands and questions for mothers of normal children and 54.70 percent for mothers of language delayed children. Results do not appear to be consistent with findings by Terdal, Jackson and Garner (1976) who report 39 percent of maternal remarks to retarded children with a mental age of 4 years, 0 months to be commands. This contrasts to findings of a higher rate of commanding in this investigation of 54.70 percent for mothers of language delayed children with a 
mean language age of 4 years, 3 months; Differences in findings may be explained again by the fact that different categories were measured, thereby affecting total percentages; other authors included mentally retarded children in their studies, as opposed to a language delayed sample in this population.

No significant difference between the two groups was found in the third area analyzed, expansions. Expansions ranked seventh in order of usage for the experimental group and eighth for the control group. This finding tends to support results of Ling and Iing (1974) and Giattino and Hogan (1975) who noted rare incidence of expansions in parent child interactions. It also supports findings by Reichle, Ionghurst and stepanich (1976) who reported no difference between mothers of two and three year olds in usage of expansions. It does not support findings by Brown and Bellugi (1964) who characterized maternal utterances to three year olds as a cycle of expansions and reductions. This may be explained by the fact that Brown and Bellugi's investigative sample included only one three year old whose language skills were considered advanced for his age. The fourth category analyzed was echoic remarks. Mothers comprising the experimental group used a mean of 2.70 percent of remarks as echoics, for a rank of six; control group mothers used a mean of 5.10 percent of remarks as echoics, ranking fifth. These results, although not statistically different, parallel Seitz and stewart's (1975) findings with maternal remarks to normal children, that as chronological age increase, echoic remarks decrease. The experimental group in this study was chronologically older than the control group. Reichle, Longhurst and Stepanich (1976) however, reported no differences on rate of echoics between mothers of normal two and three year old children. 
The fifth category analyzed consisted of remarks considered labels. No significant difference was found between the groups. Experimental mothers used 6 percent of utterances as labels, ranking fifth. Control group mothers used 4.90 percent of utterances as labels, ranking sixth. No difference was found, nor did this finding substantiate or contradict any Iiterature reported.

The sixth category analyzed included "other" remarks that could not be categorized in any of the other areas. These remarks generally included both positive and negative remarks, such as "Um-hum", "Okay", "Oh boy", "My. goodness"; "Oh-oh", "You didn't", etc. Experimental group mothers used these types of remarks second most frequently, for a mean of 23 percent. Control group mothers used these remarks third most frequently, for a mean of 20.40 percent. No statistical difference was found, nor did these findings support or contradict any findings in the literature.

The seventh category analyzed was parallel talk. Experimental group mothers used a mean of 10.20 percent of utterances as parallel talk, ranking it as the fourth most frequently used type of remark. Control group mothers used parallel talk twice as often, for a mean of 20.40 percent, ranking it as the second most frequently used type of remark. Although no reports in the literature discuss differences in the use of parallel talk between parents of normal and language delayed chilaren, these findings found significance in this study. Mothers of normal language developing children used significantly more parallel talk than mothers of language delayed children. These children also were chronologically younger than the language delayed children.

The last area analyzed was self talk. Experimental group mothers 
used a mean of 1.60 percent of utterances as self talk, ranking it as the least frequently used type of remark. Control group mothers used self talk more than twice as frequently, for a mean of 4.00 percent, ranking it as the seventh most frequently used type of remark. Again, no reports in the literature discuss differences in the use of maternal self talk to normal children or language delayed children. These results do indicate that a difference exists between maternal use of self talk to normal language developing children and language delayed children, and possibly between younger and older children. Although these results are statistically significant, this finding must be interpreted with caution; self talk comprised only 4 percent of maternal utterances in the control group. In light of the small number and percentage of self talk used, and the high standard deviation (Table IIV.), clinical significance must be interpreted with caution.

The last two categories, parallel talk and self talk, were included in this investigation because, although many textbooks for speech-language pathology students describe and encourage usage of these particular techniques, no studies were found by this investigator either comparing usage by parents of normal and language delayed children, or rate of natural occurrence among parents to language learning children. It was believed by this investigator that if a significant usage difference was demonstrated in these, or any of the other categories investigated, a scientific basis for parent education and clinical remediation could be established. If parents of normal language developing children speak differently to their young children, as has been demonstrated by a higher percentage of parallel talk and self talk in this investigation, perhaps teaching parents efficient usage of these techniques will facil- 
itate language growth in children and demonstrate itself to be a tool used in remediation.

Though not evaluated in this study, this researcher gained the impression that mothers generally either enjoyed verbal interaction and playing with their children or they did not. This apparent enjoyment was often indicated by use of parallel talk and self talk while engaged in parallel play, and was often signaled to this investigator by maternal role playing, voice changes, and other indications of verbal responsiveness. Additionally, although no child in either the experimental or control group provided all the information requested by the mother, mothers who seemed to enjoy interaction refrained from negative feedback for not being provided with correct answers. No mother who seemed to enjoy these interactions was noted to have engaged in the constraining type of questions discussed earlier in this chapter.

On the other hand, mothers who did not appear to enjoy verbal interaction with their children were observed either not to speak to their child, or to command more and/or ask questions with a constraining quality. Remarks categorized as parallel talk and self talk were noted to be more infrequent. Additionally, no sense of parallel play in the interaction was noted by this investigator. For the language delayed group, this observation may be considered a signal that parents are experiencing some sort of frustration or uncertainty regarding their child's language abilities, which may have resulted in either withdrawal from verbal interaction, or as suggested by Seitz and Marcus (1976), a higher rate of inefficient commanding and intrusiveness.

Again, although not evaluated in this study, this investigator gained the impression that perhaps the types of remarks mothers made to 
their children, especially use of parallel talk and self talk, could be viewed as an instinctive response mothers make to their children. Use of maternal parallel talk and self talk were generally effective in engaging verbal interaction with the child. Perhaps this is an example of the feedback referred to by Marshall, Hegrenes and Goldstein (1973), Seitz and stewart (1975), Seitz and Marcus (1976), Terdal, Jackson and Garner (1976) and Cunningham and Reuler (unpublished, 1977). These authors have noted differences between parents of normal and delayed children. This clear separation of groups was not apparent in this investigation although a separation appeared to emerge between mothers who seemed to enjoy interaction with their child and those who did not. Perhaps the difference between the previous investigations discussing feedback and this investigation is a by-product of socio-economic limitations and the limitations this may have on time mothers spend interacting with their child on a daily basis. All families in this study reported gross incomes at or below the poverty level. Several mothers in the experimental group who appeared to enjoy verbal interactions with their child remarked after the interaction that they wished they had more time to do this sort of thing. Although most of these parents who appeared to enjoy interactions presented their child with good language models and seemingly adequate stimulation at the time of their interaction, their children were considered language delayed. It may be interesting to note that no mother in the control group made that comment to this investigator.

A significant difference was found between mothers of $\backslash$ normal language developing children and language delayed phildren in usage of parallel talk and self talk. Mothers of children with normal language 
skills used these techniques at a significantly higher percentage than mothers of language delayed children. Perhaps results of this study indicate that teaching parents these techniques, especially parallel talk, could be an effective remediation tool for young language delayed chilaren. 


\section{CHAPTER V}

\section{SUMMARY AND IMPIICATIONS}

\section{SUMMARY}

The purpose of this study was to analyze and compare the language used by mothers of language delayed children with the language used by mothers of children with normally developing language skills when talking with their respective offspring. This investigation compared maternal remarks to language delayed offespring and maternal remarks to normal language developing offspring in an attempt to determine if and where differences occurred. The following questions were asked:

I) Do mothers of language delayed children present their children with a significantly different percentage of verbal constraints (commands and questions) than do mothers of normal language developing children in a play situation?

2) Do mothers of language delayed children present their children with an equal number of utterances as mothers of normal language developing children in a play situation?

3) Is the maternal mean length of response equal?

4) Do mothers of language delayed children present their children with a significantly different percentage of types of remarks than mothers of normal language developing children?

Mothers of twenty pre-school children were chosen from washington County Head start (Oregon) to serve as subjects. The subjects were divided into two groups on the basis of language skill level of their 
children. The control group was composed of ten mothers whose offspring demonstrated language skills at age level according to the Utah Test of Ianguage Development (Mecham, Jex and Jones, 1967). The experimental group consisted of ten mothers whose offspring demonstrated a minimum of six months delay in language skills between 2 years, 6 months and 3 years, 6 months. The mean chronological age for offspring in the control group wass 3 years, 0 months; mean age for offspring in the experimental group was 4 years, 3 months. All offspring were matched for language age equivalency. All families reported incomes at or below the poverty level most recently established by the federal government.

Maternal usage of verbal constraints (commands and questions), number of responses, mean length of response, echoics, expansions, labels, parallel talk, self talk, and other remarks were compared, using two-tailed $\underline{t}$-tests for independent means. The results indicate a statistically. significant difference exists between the two groups at the 0.05 level of probability for parallel talk and self talk. Mothers of normal language developing children used a significantly higher percentage of parallel talk and self talk than mothers of language delayed children. No other statistically significant differences were found.

In examining the data resulting from this study, it was concluded:

1) There was no statistically significant difference in percentage of verbal constraints uṣed by mothers of language delayed and normal language developing children.

2) There was no statistically significant difference in total number of responses in a ten minute period.

3) There was no statistical difference in mean length of response. 
4) Mothers of normal language developing children used a significantly highei percentage of parallel talk and self talk than mothers of language delayed children.

Perhaps results of this study indicate that teaching parents parallel talk and self talk could be an effective remediation tool for young language delayed children.

\section{IMPLICATIONS}

\section{Clinical}

One of the most important clinical implications for the speechlanguage pathologist arising from this study is: If parent training is utilized as a remediation tool for the young language delayed child, teaching the mother effective use of parallel talk and perhaps self talk techniques may have an important effect upon the development of language skills of the child. Teaching these particular techniques may have more effect on language skills of the young child than any of the other techniques compared.

Additionally, teaching mothers to command less may have an effect on children's language skilis. Certainly, the techniques known as parallel talk and self talk cannot be utilized as directives or commands. $\underline{\text { Research }}$

The small number of subjects in this study limits the extent to which generalizations can be made based on these results. In this study, mothers of language delayed children demonstrated a few significant differences in the types of remarks made to their pre-school offspring. Primarily, mothers of language delayed children demonstrated a significantly smaller percentage of parallel and self talk type remarks than 
mothers of normal language developing children. Further research with larger numbers of subjects is needed to examine and substantiate these. findings.

Additionally, the nature of questions (constraining vs. nonconstraining) and commands could be examined to determine if there is a difference in truly constraining remarks.

This investigation compared maternal mean length of response as prescribed by Johnson, Darley and Spriesterbach (1963) (Appendix F) between the two groups. It would be of interest to compare mean length of utterance as prescribed by Brown (1973), who counted morphological units rather than words. This comparison may provide some different information about maternal language models that mean. length of utterance may not.

It would also be interesting to investigate the types of maternal remarks made to normal and language delayed children across socio-economic lines. Would differences emerge if mothers in various socio-economic groups interact with children in another socio-economic group? Would differences emerge if mothers of normal children interacted with language delayed children within and/or across socio-economic levels?

In addition, the effects of clinical intervention with mothers and children would be of interest. Would teaching only parallel talk and self talk techniques to mothers effect a significant change in young children's language skills? Or would teaching these techniques in conjunction with direct clinical intervention with the child effect a greater or faster change?

The results of these studies may have an important impact on both direct clinical intervention with the young language delayed child and 
parent education strategies. 
BAYLES, K.A., The effects of constraint and nonconstraint on the verbal behavior of pre-school children. Master's thesis, Arizona state University (1974), as reported in Hubbell, R.D., On facilitating spontaneous talking in young children. JSHD, 43, 216-231 (1977).

BERRY, M. and Eisenson, J., Speech Disorders: Principles and Practices of Therapy. New York: Appleton-Century-Crofts (1956).

BROEN, P.A., The verbal environment of the language-learning child. JSHD Monograph Supplement, 17 (1972).

BROWN, R., A First Language, the Early Stages. Cambridge, Mass.: Harvard University Press (1973).

BROWN, R. and Bellugi, U., Three processes inthe child's acquistion of syntax. Harvard Educational Review, 34, 133-151 (1964).

CAZDEN, C., Environmental assistance to the child's acquisition of grammar. Dissertation Abstracts International, 29, 2144-2145 (1969).

CUNNINGHAM, C. and Rueler, E., A comparative analysis of the relationship between the language patterns and interactions of normal and retarded children and their mothers. Unpublished, (1977).

FRIEDLANDER, B.Z., Jacobs, A., Davis, B.B., and Wetstone, H.S., Time sampling analysis of infants' natural language environment in the home. Child Development, 43, 730-740 (1972).

GIATrINO, J. and Hogan, J.G., Analysis of a father's speech to his language learning child. JSHD, 41, 524-537 (1975).

JOHNSON, W., Darley, F.I. and Spriesterbach, D.C., Diagnostic Methods in Speech Pathology. New York: Harper and Row (1963).

LEE, L. Developmental Sentence Analysis. Evanston, Illinois: Northwestern University Press (1974).

LING, D. and Ling, A.H., Communication development in the first three years of life. JSHR, 17, 146-159 (1974).

MALOUF, R.E. and Dodd, D.H., Role of exposure, imitation and expansion in the acquisition of an artificial rule. Developmental Psychology,

7. 195-203 (1972). 
MARSHAII, N.R., Hegrenes, J.R., and Goldstein, S., Verbal interactions: mothers and their retarded children vs. mothers and their nonretarded children. American Journal of Mental Deficiency, 77, 415419 (1973).

MECHAM, M., Jex, L., and Jones, L., Utah Test of Language Development. Salt Iake City, Utah: Communication Research Associates (1967).

MOERK, E.I., Principles of dyadic interaction in language learning. Merrill-Palmer guarterly, 18, 229-257 (1972).

MOERK, E.I., Processes of language teaching and language training in the interactions of mother child dyads. Child Development, 47, 10641078 (1976).

PHILIPS, J.R., Formal characteristics of speech which mothers address to their young children. Dissertation Abstracts International, 31, 4369-4370 (1971).

REICHIE, J.E., Longhurst, T.M., and Stepanich, I., Verbal interaction in mother-child dyads, Developmental Psychology, 12, 273-277 (1976).

SEITZ, S. and Hoekenga, R., Modeling as a training tool for retarded children and their parents. Mental Retardation, 12, 28-31 (1974).

SEITZ, S. and Marcus, S., Mother-child interactions: a foundation for language development. Exceptional Children, 42, 445-449 (1976).

SEITZ, S. and Riedell, G., Parent-child interactions as the therapy target. J. Commun. Dis., 7, 295-304 (1974).

SEITZ, S. and Stewart, C., Imitations and expansions: some developmental aspects of mother-child communications. Developmental Psychology, $11,763-768$ (1975).

SKINNER, B.F., Verbal Behavior, New York: Appleton-Century-Crofts (1957).

SNOW, C.E., Mothers' speech to children learning language. Child Development, 43, 549-565 (1972).

TERDAL, L., Jackson, R.H., and Garner, A.N., Mother-child interactions: a comparison between normal and developmentally delayed children, from Mash, E.J., Hamerlynck, L.A. and Handy, L.C., Behavior Modification and Families, New York: Brunner, Mazel, Inc. (1976).

VAN RIPER, C., Speech Correction, Principles and Methods, New Jersey: Prentice Hall (1972).

WULBERT, M., Inglis, S., Kriegsmann, E., and Mills, B., Language delay and associated mother-child interactions. Developmental Psychology, $11,61-70$ (1975). 
APPENDIX A

IANGUAGE AGE, CHRONOLOGICAI AGE, AND SEX OF MATCHED OFFSPRING

I.A.

C.A.

Sex

Experimental 1

Control 1

Experimental 2.

Control 2

Experimental 3

control 3

Experimental 4

Control 4

Experimental 5

Control 5

Experimental 6

Control 6

Experimental 7

control 7 .

Experimental 8

Control 8

Experimental 9

Control 9

Experimental 10

Control 10
$2-6$

2-6

4-3

$2-7$

M

M

2-7

$2-7$.

3-9

2-7

M

F

2-9

4-6

$2-10$

M

$2-10$

$3-4$

2-10

M

2-10

2-10

$2-10$

2-11

4-0

3-0

4-3

3-1

4-8

$3-1$

4-8

$3-3$

4-0

3-7

4-II

3-7

M

M

F.

M

F

M

M

F

3-5

3-4

3-6

3-6

3-6

3-6

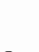

$M$

.

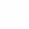

1

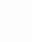




\section{APPENDIX B}

ADMINISTRATION FOR CHIIDREN, YOUTH AND FAMILY NOTICE FAMIIY INCOME GUIDELINES FOR 1978 1978 FAMTLY INCOME GUIDELINES FOR ALI STATES

EXCEPT ALASKA AND HAWAII

$\$ 3,140$

4,160

5,180

6,200

7,220

8,240
$\$ 2,690$

3,550

4,410

5,270

6,130

6,990

For family units with more than 6 members, add $\$ 1,020$ for each additional member in a nonfarm family and $\$ 860$ for each additional member in a farm family.

$(2 / 17 / 78)$ 
APPENDIX C

MODIFICATION OF

PARENT-CHILD INTERACTION SCORESHEET

Name:

Ianguage Age Equivalent:

Chronological Age:

Questions:

Commands :

Echoics :

Expansions :

Iabel:

Parallel Talk:

Self Talk:

Other: 
APPENDIX D

TRANSCRIPT OF INFORMATION GIVEN TO PARENTS

Initial Telephone Contact

He110, (name of mother) _. This is Vanessa Bunker from

Head start. I am in the process of conducting a study on speech and language skills of children and what mothers say to children of different ages. I understand you have a year old.

Would you be interested in participating in my study? I would need to have you spend fifteen minutes in a room at Head start playing and talking with him/her just as you would at home. You will be in a room alone and I will tape record everything you and your child say, and then compare it with other mothers and children later. I will also give (name of child) a free hearing check and another quick test to see how his/her language skills are coming along. All together, it should take about 30-45 minutes.

\section{Instructions Given at Time of Research}

I want you and (name of child) to play and talk just as you would at home for fifteen minutes. There are toys in here and you can use them or not use them--whatever you would like. I'll come back in again in fifteen minutes. The only requirement is that you stay in this room until I come back. (All questions were answered with: "Do what makes you feel comfortable", or "Let's talk about that afterwards." 


\section{APPENDIX E}

\section{GUIDELINES .FOR COUNTING NUMBER OF .UTTERANCES}

1) Misarticulations and/or mispronounciations will not be penalized.

2) Nonfluencies, grammatical reformulations, and repetitions resulting from word.finding problems will be transcribed, but counted as one utterance.

The following were each counted as one utterance:

a) He (gave:..gave...gave it to) gave it to the dog.

b) (Where's the... where's the) what's he doing?

c) He went (to see) to get the ball.

d) (He saw...he saw...) what's that thing called?

3) An utterance need not be grammatically correct or complete to be counted; it need only have a subject and a verb.

The following were each counted as one utterance:

a) He ain't' in the car no more.

b) The boys is coming.

c) Doggie eating.

4) Interjections and/or single words will be counted as independent utterances if uttered as such.

The following words were included in this category: yes, no, okay, oh-oh, bye-bye, night-night, hey, sh, oops, wow, ow, and oh.

They will be counted as part of the utterance if uttered as such. Examples of this include:
a) Okay, I'll hurry.
b) Time to go night-night. 
6) A maximum of one "and" conjunction is allowed per utterance when the conjunction separates two independent clauses not separated by a vocal pause.

The following were each counted as one utterance:
a) There goes the car and it's going fast.
b) (And) it's going to crash and the man got scared.
c) (And) screamed "Help!" and "Stop the car!".
7) Unintelligible utterances will be excluded. 
APPENDIX F

GUIDELINES FOR COUNTING MEAN IENGTH OF RESPONSES

(taken from: Johnson, W., Darley, F.L. and Spriesterbach, D.C., Diagnostic Methods in Speech Pathology, New York: Harper and Row (1963).)

1. Contractions of the subject and predicate like "let's" and "you're" are counted as two words.

2. Contractions of the verb and the negative like "can't" are counted as one word.

3. Hyphenated words and compound nouns, particularly proper nouns that are not hyphenated but function as single words and as names of single objects, are counted as single words. Examples: "merry-go-round", "Mother Goose", "Betty Lou".

4. Each part of a verbal combination is counted as a separate word. Example: "Have been playing" would be counted as three words.

5. "Lookit" is counted as one word if it occurs alone and functions simply as "look"; if followed by an object it is counted as the two words "look at".

6. Each of the following is to be counted as one word: oh boy, my gosh, darn it, doggone it, all right, maybe, giddy-up, someone, lighthouse, birdhouse, high school, ain't.

7. Each of the following is to be counted as two words: oh yes, oh no, oh gee, on to, Christmas tree, kinda, oughta, hafta.

8. Since repetitions can add substantially to the length of the uttered response, they should be excluded according to the following rules:

a) Word repetition. When the same word is repeated several times consecutively it should be counted only once: "He (he he) went home." "The boy ran ( $\operatorname{ran}$ ) he ran away." The words in parenthesis should not be counted.

b) Phrase repetition. When a phrase is repeated it should be counted only once: "He was (he was) hurt." "And he hit (and he hit) him." You would not count the words in parenthesis. However, if at least one different word is added when a phrase is ,repeated, all the words in the repetition should be included in the total count: "And he hit-and he spanked him." "They were going, they were having fun." Word repetition within a phrase repetition does not nullify a phrase repetition; "And he's (he's he's--and he's home." The words in parenthesis should not be counted. Contractions should be separated for purposes of this analysis and not be 
considered to nullify a repetition: "He's eating, (he is eating) the mouse." The words in parenthesis should not be counted. This procedure should be followed for word repetition also.

c) Repetitions not excluded. When a child repeats a word for enumerative purposes and for starting a new thought unit, he should not be penalized for repetition. "That's a bear there, that's a bear there, that's. a bear there." "I think that that is a bear." "That's what they are, they're bears." Both "that" and "they're" are to be judged as part of a new subordinate or independent clause and are to be counted. Where it cannot be determined whether a repetition is used for emphasis or constitutes a disfluency, the repetition should be excluded.

9. Words not completed by the individual should be recorded as though they were completed. Examples: "I thi (think)--I know he's going home." It is especially important to follow this procedure with regard to the analysis of repetition. In many instances a child repeats phrases but does not complete words within the phrase. Example: "(I thi--(think) he)-I think he went home." This sentence should be judged to include a phrase repetition, since it could hardly be interpreted as "I he, I think he went home." The words in parenthesis would, therefore, not be counted in determining the number of words in the speech sample.

10. Noises should be counted only when they are considered to be an integral part of the sentence. "Ahhh grrr, the lion is eating the monkey," "The lịon is going to grrr the monkey." In the first sentence the "Ahhh grrr" can be considered unessential and should be excluded as not indicative of the child's linguistic maturity. In the second instance the "grrr" takes the part of the verb and should be included.

11. Interjections not considered dictionary items and functioning solely to connect words or phrases should not be counted: "er," "um," etc. However, like utterances which serve as words should be counted: "Uh-huh," "hmmmm"--the first of these serves as a substitute for the affirmative word "yes" and the second as the negative word "no".

12. All colloquialisms and neologisms should be counted: "wham," "whoops," "yike," "ya," "yippee," "teensy-weensy," "naw," "yeah," etc. 